\section{Plant Regeneration and an Analysis of Somaclonal Variation from TifEagle and TifSport Bermudagrass Cultivars}

\author{
Jason J. Goldman ${ }^{1}$ and Wayne W. Hanna \\ Department of Crop and Soil Sciences
}

\author{
Peggy Ozias-Akins ${ }^{2}$ \\ Department of Horticulture, P.O. Box 748, University of Georgia, Tifton \\ Campus, Tifton, GA 31793
}

Additional index words. Cynodon dactylon x Cynodon transvaalensis, somatic embryogenesis, MS medium, 2,4-D, 6-benzyladenine

\begin{abstract}
TifEagle' ( $2 n=3 x=27)$ hybrid bermudagrass [Cynodon dactylon (L.) Pers. ( $2 n$ $=4 x=36) \times$ Cynodon transvaalensis Burtt-Davy $(2 n=2 x=18)]$ is an ultradwarf cultivar for greens, and 'TifSport' $(2 n=3 x=27)$ is a more versatile hybrid used on fairways, athletic fields, and lawns. To develope a transformation system and determine if somaclonal variation was present in regenerated plants, both cultivars were tested for their ability to produce embryogenic callus from which plants could be regenerated. Sliced nodes of both cultivars and immature inflorescences from 'TifSport' were used as the explant sources. Cultures were initiated on Murashige and Skoog medium supplemented with $6.79 \mu \mathrm{M}$ 2,4-D and 0.044 $\mu \mathrm{M}$ BA ('TifSport' and 'TifEagle') or 6.79 $\mu \mathrm{M} 2,4-\mathrm{D}$ plus $200 \mathrm{mg} \cdot \mathrm{L}^{-1}$ casein hydrolysate ('TifSport'). In total, 51 plants were regenerated from callus of a single node of 'TifEagle'. Nodes from 'TifSport' did not produce embryogenic callus. In total, 29 plants were regenerated from callus of 'TifSport' produced from immature inflorescences. These plants were grown in the field for at least one season, and 5-cm-diameter plugs were harvested, repotted in a greenhouse, and allowed to reestablish. Data on canopy height, leaf width, leaf length, and number of stolons were collected. Seven 'TifEagle'-derived entries (14\%) were not significantly different $(\alpha=0.05)$ from 'TifEagle' harvested from the breeder plot in Tifton, Ga., for all measured traits, and $41 \%, 24 \%$, and $22 \%$ differed by one, two, or three measurements, respectively. Flow cytometry indicated that $33 \%$ (13 plants) of the 'TifEagle' regenerants were hexaploid $(2 n=6 x=54)$ and the rest remained triploid. One 'TifSport' regenerant was significantly different $(\alpha=0.05)$ for plant height.
\end{abstract}

Tetraploid bermudagrass [Cynodon dactylon (L.) Pers. $(2 n=4 x=36)]$ and diploid bermudagass [Cynodon transvaalensis Burtt-Davy $(2 n$ $=2 x=18$ )] are perennial, warm-season grasses that have characteristics desirable for turf. Triploid $(2 n=3 x=27)$ hybrid bermudagrass can be produced by an interspecific cross between Cynodon dactylon and Cynodon transvaalensis, resulting in progeny that produce no seed and sterile pollen. 'TifEagle' hybrid bermudagrass (Hanna and Elsner, 1999) was derived from stolons of 'Tifway 2', which were irradiated with 7000 rads of gamma radiation from ${ }^{60} \mathrm{Co}$, and isideal for putting greens. 'TifSport' (Hanna et al., 1997) is a fine-textured mutant derived from irradiating 'Midiron' stolons with 8000

\footnotetext{
We gratefully acknowledge Anne Bell, Wynn Bloodworth, Jacolyn Merriman and the turf genetics group at the University of Georgia Coastal Plan Experiment Station at Tifton for excellent technical assistance and for moving plants to the field. We thank Benjamin Mullinix for statistical assistance and Earl Elsner for shipping plant material from Athens Ga., and the University of Georgia Research Foundation and the Georgia Seed Development Commission for financial support.

${ }^{1}$ Current address: Southern Plains Range Research Station, $200018^{\text {th }}$ Street, Woodward, OK 73801.

${ }^{2}$ To whom reprint requests should be addressed; e-mail Ozias@tifton.uga.edu.
}

rad of gamma radiation $\left({ }^{60} \mathrm{Co}\right)$. 'TifSport' is a cold-tolerant versatile hybrid used on fairways, athletic fields, landscapes, and lawns.

Tissue culture alone is thought to be a source of somaclonal variation and or mutation. Somaclonal variation was reported for bermudagrass (Cynodon dactylon) by Croughan et al., (1994). Variation among tissue culture-derived plants can be due in part to chromosome instability in tissue culture (Ahloowalia, 1975, 1983). Increased ploidy ( $2 \mathrm{x}$ to $4 \mathrm{x}$ ) was observed at low frequency ( $0 \%$ to $4.3 \%$ ) among nontransgenic barley regenerants and a higher frequency of polyploidy (46\%) was observed with plants that were transformed (Choi et al., 2000).

Currently there are a limited number of reports on tissue culture and plant regeneration of bermudagrass (Ahn et al., 1985, 1987; Artunduaga et al., 1988, 1989; Chaudhury and Qu, 2000; Li and Qu, 2002). There appears to be a genotype effect for desirable tissue culture response and all of these reports employed explants from immature inflorescences. 'TifEagle' produces only a few inflorescences, which is desirable from a golf management viewpoint but limits the choices for suitable explants for culture initiation. Recently, Zhang et al. $(2002,2003)$ used nodes of 'TifEagle' for plant regeneration and observed somaclonal variation. The nature and extent of variation was not described and their protocol involved a lengthy liquid culture phase before plant regeneration. The objectives of our study were to 1) determine if the immature inflorescence from 'TifSport' or the node from 'TifSport' and 'TifEagle' were suitable explants for embryogenic tissue production and plant regeneration, and 2) document any somaclonal variation present in regenerated plants by morphological and DNA content measurements.

\section{Materials and Methods}

Node culture. 'TifEagle' plants were harvested from the breeder plot in Tifton, Ga., and repotted in the greenhouse. Stolons hanging over the edge of the pots were harvested and segments $\approx 2 \mathrm{~mm}$ containing individual nodes were cut from the stolons and placed in a $100 \times 15-\mathrm{mm}$ petri dish. Nodes were surface sterilized by rinsing in $70 \%$ ethanol for $1 \mathrm{~min}$. The ethanol was removed, and a small stir-bar was added along with $20 \mathrm{~mL}$ $17 \%$ Ultra-Clorox (contains $6.15 \%$ sodium hypochlorite) and allowed to spin for $20 \mathrm{~min}$. Four rinses in sterile water were performed before nodes were used for culture. Nodes were sliced longitudinally, one to four times and plated, sliced side down in $100 \times 15-\mathrm{mm}$ petri dishes containing $20 \mathrm{~mL}$ of Murashige and Skoog (1962) medium supplemented with $4.52 \mu \mathrm{M}$ 2,4-dichlorophenoxyacetic acid (2,4-D), $0.044 \mu \mathrm{M}$ 6-benzylaminopurine (BA) (Chaudhury and Qu, 2000), $40 \mathrm{~g} \cdot \mathrm{L}^{-1}$ sucrose, and 7.5 g. $\mathrm{L}^{-1}$ agar (A1296 Sigma Chemical Co., St. Louis, Mo.) adjusted to a $\mathrm{pH}$ of 5.8. Filtersterilized BA was added after autoclaving (20 min, $121{ }^{\circ} \mathrm{C}, 105 \mathrm{kPa}$ ) along with $1 \mathrm{~mL} \cdot \mathrm{L}^{-1}$ Plant Preservative Mixture (PPM) (Plant Cell Technologies, Inc., Wash., D.C.). 'TifSport' nodes were cultured the same way. For the frequency of embryogenic tissue production, a single node, irrespective of the number of times it was sliced before plating, was used for data collection. Data were collected as present or absent in terms of embryogenic tissue production starting $30 \mathrm{~d}$ after culture initiation and continued for up to 8 weeks after initiation. The quantity of embryogenic tissue after an initial sighting, per node, was not considered.

Inflorescence culture. Plugs of 'TifSport' thought to contain immature inflorescences were harvested during May and June from the Tifton breeder plot or from Athens, Ga. Inflorescences in the boot, free of soil or extraneous leaf material, were surface sterilized in the same manner as nodes but in a Magenta vessel. Immature inflorescences (5 to $10 \mathrm{~mm}$ long) were cultured on the same induction medium as nodes or on MS $+6.79 \mu \mathrm{M} 2,4-\mathrm{D}$ $+40 \mathrm{~g} \cdot \mathrm{L}^{-1}$ sucrose $+200 \mathrm{mg} \cdot \mathrm{L}^{-1}$ casein hydrolysate. Nodes and immature inflorescences were cultured in the dark at $28^{\circ} \mathrm{C}$.

Plant regeneration from embryogenic tissue of both genotypes was initiated by fracturing and culturing tissue on $0.59 \mu \mathrm{M} 2,4-\mathrm{D}+2.2 \mu \mathrm{M}$ BA (Taylor and Vasil 1996) in the light (average of $\left.100 \mu \mathrm{mol} \cdot \mathrm{m}^{-2} \cdot \mathrm{s}^{-1}\right)$. Germinating somatic embryos were induced to elongate and root on agar-solidified basal MS in $100 \times 25$-mm petri dishes. Rooted plantlets were transferred to 
polypropylene round bottom tubes $(17 \times 100$ $\mathrm{mm}$ ) containing $7 \mathrm{~mL}$ medium for further shoot elongation and root development. Plants were then transferred to soil and hardened off under a 250-W metal halide lamp for a few days before being moved to greenhouse benches.

Somaclonal variation. After plants were cultivated for at least one season under standard field conditions and mowing practices, four $5-\mathrm{cm}$ plugs were taken from each entry and planted in $15-\mathrm{cm}$ pots in the greenhouse. Plants were arranged in a randomized complete block design with four replications. Plugs from 'TifEagle' and 'TifSport' breeder plots were used as controls. 'TifEagle' and 'TifSport' plants were treated as two separate experiments. To detect somaclonal variation, measurements included plant height $(\mathrm{cm})$, leaf width ( $\mathrm{mm}$, three leaves), and leaf length $(\mathrm{cm}$, three leaves). For 'TifEagle', the number of stolons that were hanging at least $8 \mathrm{~cm}$ over the edge of the container also were counted as a measure of vigor. PROC MIXED (SAS
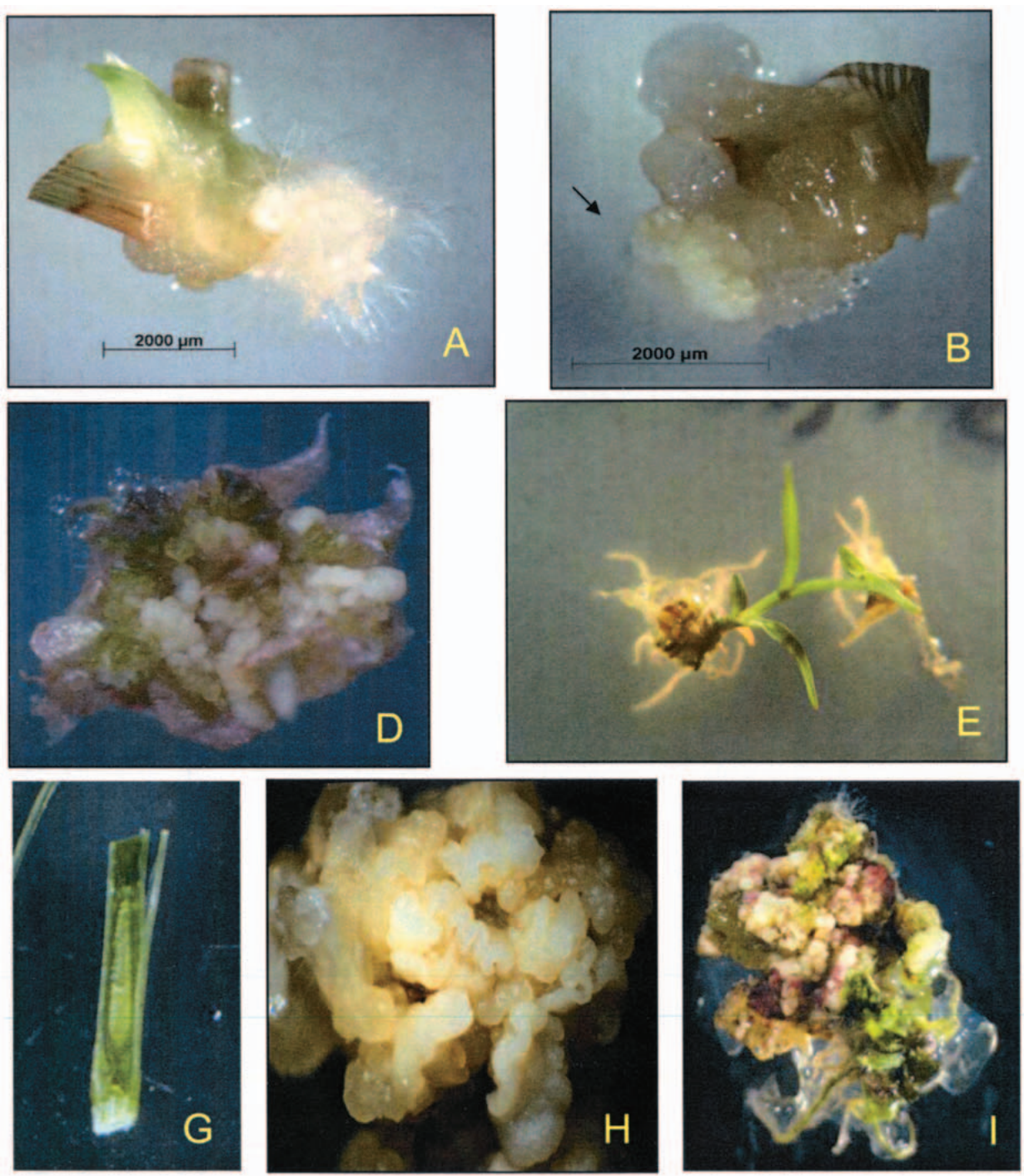

Institute, 1999) and multiple $t$ tests on differences of least square means were used to detect significant differences $(\alpha=0.05)$ between regenerated plants and checks of 'TifEagle' and 'TifSport' harvested from the breeder plot in Tifton, Ga.

Flow cytometry. Fresh young leaves (approximately $0.5 \mathrm{~cm}^{2}$ ) harvested from 'TifEagle'-derived regenerated plants located in the field were chopped with a double-edged razor blade in $400 \mu \mathrm{L}$ of commercial Partec (Partec GmbH, Otto-Hahn Straße 32, D-48161 Münster, Germany) nuclei extraction buffer solution to release nuclei. The suspension was poured through a $50-\mu \mathrm{m}$ filter to remove debris and $1.6 \mathrm{~mL}$ of commercial Partec DAPI staining buffer solution was added to the filtrate. The suspension was analyzed on a flow cytometer (Partec Cell Analyzer PAS III) and allowed to count for at least 10,000 fluorescent particles. Peak means were calculated by an internal peak analysis program of the flow cytometer. Control 'TifEagle' (3x), was routinely run (every fifth sample) as an external standard. Ploidy level was determined based on position of the G1 peaks of regenerated plants relative to the $3 \mathrm{x}$ standard.

\section{Results and Discussion}

Nodes. 'TifEagle' cultivated in pots produced an abundant supply of nodes for culture initiation. The aerial nodes were free of soil, did not have visible axillary shoots, and were easy to harvest. When plated on $\mathrm{MS}+4.5$ $\mu \mathrm{M} 2,4-\mathrm{D}+0.044 \mu \mathrm{M} \mathrm{BA}+40 \mathrm{~g} \cdot \mathrm{L}^{-1}$ sucrose, nodes were capable of producing embryogenic tissue suitable for plant regeneration. The initial explant increased in size over the first 3 weeks in culture, mainly by producing nonembryogenic tissue and occasional shoots (probably from preexisting axillary meristems) (Fig. 1A). Because of the rapid increase in explant size, plating five nodes per dish, each sliced in half, allowed ample room for growth within the first $30 \mathrm{~d}$ of culture. Embryogenic

Fig. 1. 'TifEagle' node 1 week after culture initiation beginning to produce primary nonembryogenic tissue (A). Pale yellow (B) and white (C) 'TifEagle' nodederived embryogenic tissue. 'TifEagle' embryogenic tissue after transfer to germination medium (D) followed by shoot elongation and rooting on basal MS medium $(\mathbf{E})$. 'TifEagle' regenerated plants after being moved in from the field $(\mathbf{F})$. Cross section of a blade of 'TifSport' grass containing an immature inflorescence suitable for culture initiation $(\mathbf{G})$. 'TifSport' embryogenic tissue $(\mathbf{H})$ after being placed on germination medium (I). 'TifSport' derived regenerated plants before transfer to the field $(\mathrm{J})$. 
tissue often was not observed until a portion of nonembryogenic, watery, friable tissue was removed, revealing a small pale-yellow to white piece of embryogenic tissue embedded inside. These pieces of embryogenic tissue were not physically attached to the nonembryogenic tissue and could be easily removed. In other cases the embryogenic tissue could be observed before subculture, often by viewing the explant from the underside of the culture dish. In no case was embryogenic tissue observed to form before the initiation of nonembryogenic tissue. The frequency of embryogenic tissue production per node was $36 \%(21 / 58)$ for 'TifEagle'. 'TifSport' nodes did not produce embryogenic callus.

In a 'TifEagle' pilot study, a small piece of embryogenic tissue was observed to originate from the underside of a single nodal explant $\approx 5$ weeks after culture initiation, similar in appearance to Fig. 1B and C. Upon transfer to $0.59 \mu \mathrm{M} 2,4-\mathrm{D}+2.2 \mu \mathrm{M} \mathrm{BA}$ in the light, this original piece of embryogenic tissue rapidly proliferated to form pale-yellow embryogenic tissue. After subculture to the same medium by fracturing to increase the number of discrete pieces of tissue, the embryogenic tissue responded by turning a variety of colors, ranging from light pink to dark purple (Fig. 1D). Some tissues also developed opaque, white somatic embryos, which germinated and formed green shoots. Once embryo germination was induced on $0.59 \mu \mathrm{M} 2,4-\mathrm{D}+2.2 \mu \mathrm{M}$ BA medium, embryos were separated from the source callus and allowed to elongate and root on basal MS medium (Fig. 1E). Transfer of plants to tubes was an efficient way to promote a strong root system and maximize shoot elongation potential. In total, 51 plants were regenerated from the single piece of embryogenic tissue isolated from a single node (Fig. 1F). The time frame from culture initiation to rooted plant ranged from 87 to $125 \mathrm{~d}$.

Inflorescence. 'TifSport' only flowers for a short time during May and June and it was difficult to determine when to harvest immature inflorescences at the ideal size for culture initiation (Fig. 1G). Once a flag leaf was apparent, the inflorescence was too mature to respond to the induction media tested. Although both media induced embryogenic tissue, the frequency was low. Out of 282 inflorescences, 45 (16\%) formed embryogenic tissue on $\mathrm{MS}+4.5 \mu \mathrm{M}$ $2,4-\mathrm{D}+0.044 \mu \mathrm{M} \mathrm{BA}+40 \mathrm{~g} \cdot \mathrm{L}^{-1}$ sucrose, and 27 out of $368(7 \%)$ responded on $\mathrm{MS}+6.79$ $\mu \mathrm{M}$ 2,4-D + $200 \mathrm{mg} \cdot \mathrm{L}^{-1}$ casein hydrolysate. In most cases, embryogenic tissue became evident only after the third or fourth 2-week transfer (Fig. 1H). The regeneration response of 'TifSport' was similar to 'TifEagle' after transfer of embryogenic tissue to medium containing 0.59 $\mu \mathrm{M} 2,4-\mathrm{D}+2.2 \mu \mathrm{M}$ BA (Fig. 1I). A total of 31 plants were regenerated and used for analysis of somaclonal variation (Fig. 1J).

The frequency of somatic embryo germination was unpredictable and low for both cultivars. Although 51 plants were regenerated from a single small piece of embryogenic tissue ('TifEagle'), in many cases, tissue required multiple transfers between basal MS and medium supplemented with $0.59 \mu \mathrm{M} 2,4-\mathrm{D}$
$+2.2 \mu \mathrm{M}$ BA to induce germination. In other cases, somatic embryos failed to germinate and eventually senesced and died.

Somaclonal variation. Somaclonal variation was clear by casual observations for 'TifEagle' but not for 'TifSport' and was confirmed by actual measurements (Table 1). Seven 'TifEagle'-derived entries $(14 \%)$ were not significantly different $(\alpha=0.05)$ from the 'TifEagle' control for all measured traits, and $41 \%, 24 \%$, and $22 \%$ differed by one, two, or three measurements, respectively. On an individual trait basis, $37 \%$ differed for leaf width, $18 \%$ for plant height, $24 \%$ for leaf length, and $75 \%$ for number of stolons, from the
'TifEagle' control. Flow cytometry indicated that 13 plants $(34 \%)$ were hexaploid and the rest remained triploid. Recently, Goldman et al (2003), combined this system with biolistic based transformation and found that 82/89 transgenic plants regenerated were hexaploid and exhibited most of the somaclonal variation present. Only the triploids retained all the characteristics of control 'TifEagle'. Hexaploids generally were darker green, taller, and had wider leaves compared to the triploids. Many of the hexaploids lacked vigor in the field and turned a deep purple color in the fall. Regenerated plants of 'TifSport' did not exhibit the extent of somaclonal variation

Table 1. Degree of somaclonal variation present in 'TifEagle'- and 'TifSport'-derived regenerated plants

\begin{tabular}{|c|c|c|c|c|c|}
\hline In vitro period (d) & Plant no. & Plant ht & Leaf width & Leaf length & No. stolons \\
\hline \multicolumn{6}{|l|}{ 'TifEagle' } \\
\hline \multirow[t]{5}{*}{87} & 1 & 4.0 & $1.5^{*}$ & 2.0 & 40.25 \\
\hline & 2 & 4.5 & 1.04 & 2.29 & $24.75^{* *}$ \\
\hline & 3 & 2.96 & 1.01 & 2.04 & 51.93 \\
\hline & 4 & 4.13 & 1.16 & 2.25 & 34.25 \\
\hline & 7 & 4.88 & 1.12 & 2.16 & 34.5 \\
\hline \multirow[t]{7}{*}{91} & 9 & 5.25 & $1.87^{* * * *}$ & $2.83^{* *}$ & $11.25^{* * *}$ \\
\hline & 10 & 4.5 & 1.16 & 2.37 & $6.25^{* * *}$ \\
\hline & 11 & 4.20 & $2.0^{* * * *}$ & 2.54 & $15.0^{* * *}$ \\
\hline & 13 & $5.5^{*}$ & 1.04 & 2.37 & $27.75^{*}$ \\
\hline & 15 & 4.75 & $1.83^{* * * *}$ & $2.66^{*}$ & $12.5^{* * * *}$ \\
\hline & 16 & 4.75 & 1.20 & $2.83^{* *}$ & $10.0^{* * * *}$ \\
\hline & 18 & 5.0 & 1.25 & 2.45 & $29.25^{*}$ \\
\hline \multirow[t]{8}{*}{95} & 19 & 4.38 & 1.04 & 2.12 & $29.5^{*}$ \\
\hline & 20 & 4.75 & 1.16 & 2.12 & 38.5 \\
\hline & 22 & 5.25 & 1.37 & 2.41 & 34.0 \\
\hline & 23 & 5.0 & 1.20 & 2.54 & $22.25^{* * *}$ \\
\hline & 24 & $5.5^{*}$ & $1.41^{*}$ & 2.25 & $29.25^{*}$ \\
\hline & 25 & $7.0^{* * *}$ & 1.25 & $2.95^{* * *}$ & $26.25^{* *}$ \\
\hline & 26 & 4.75 & 1.04 & 2.5 & $28.0^{*}$ \\
\hline & 27 & 5.0 & $1.41^{*}$ & $2.95^{* * * *}$ & $6.5^{* * * *}$ \\
\hline \multirow[t]{9}{*}{98} & 28 & 5.0 & $1.75^{* * *}$ & $2.62^{*}$ & $18.5^{* * *}$ \\
\hline & 29 & 4.25 & 1.16 & 2.29 & $29.5^{*}$ \\
\hline & 30 & $5.75^{* *}$ & 1.33 & 2.29 & 36.5 \\
\hline & 31 & 4.5 & $1.79^{* * * *}$ & $2.58^{*}$ & $19.0^{* * * *}$ \\
\hline & 32 & $6.25^{* *}$ & 1.29 & $2.79^{* *}$ & 31.0 \\
\hline & 33 & 4.75 & $1.79^{* * * *}$ & 2.45 & $10.75^{* * *}$ \\
\hline & 34 & 5.0 & 1.0 & 1.95 & $24.25^{* *}$ \\
\hline & 35 & 3.88 & $1.66^{* * * *}$ & 2.08 & $15.25^{* * *}$ \\
\hline & 36 & 4.75 & 1.33 & 2.33 & $20.0^{* * * *}$ \\
\hline \multirow[t]{7}{*}{101} & 38 & 5.25 & $1.87^{* * * *}$ & $2.70^{* *}$ & $16.5^{* * *}$ \\
\hline & 39 & 4.75 & $1.5^{*}$ & 2.41 & $14.75^{* * *}$ \\
\hline & 40 & 5.0 & 1.04 & 2.16 & $19.25^{* * *}$ \\
\hline & 42 & 5.25 & 1.16 & 2.25 & 35.25 \\
\hline & 43 & 5.0 & 1.16 & 2.46 & $27.75^{*}$ \\
\hline & 44 & 4.75 & $2.0^{* * * *}$ & $2.58^{*}$ & $19.5^{* * *}$ \\
\hline & 45 & 5.0 & $1.62^{* *}$ & 2.31 & $17.5^{* * *}$ \\
\hline \multirow[t]{7}{*}{114} & 46 & $5.75^{* *}$ & 1.29 & 2.16 & 33.5 \\
\hline & 47 & 4.75 & $1.45^{*}$ & 2.5 & 32.0 \\
\hline & 48 & 4.5 & 1.25 & 2.16 & $25.25^{* *}$ \\
\hline & 49 & $5.75^{* *}$ & 1.29 & 2.29 & 34.0 \\
\hline & 50 & $5.75^{* *}$ & 1.14 & 2.45 & $29.75^{*}$ \\
\hline & 51 & 4.88 & $1.45^{*}$ & 2.16 & $28.75^{*}$ \\
\hline & 52 & 5.0 & 1.04 & 2.41 & $27.0^{*}$ \\
\hline \multirow[t]{8}{*}{121} & 53 & 5.0 & 1.12 & 2.16 & $28.0^{*}$ \\
\hline & 54 & 4.25 & $1.5^{*}$ & 2.5 & $7.5^{* * * *}$ \\
\hline & 55 & 5.5 & 1.12 & 2.29 & $29.0^{*}$ \\
\hline & 56 & 4.25 & $1.5^{*}$ & $2.70^{* *}$ & $13.75^{* * *}$ \\
\hline & 57 & 4.44 & 1.36 & 2.09 & $14.66^{* * * *}$ \\
\hline & 58 & 4.75 & 1.25 & 2.12 & $29.25^{*}$ \\
\hline & 59 & 4.46 & $1.79^{* * *}$ & $2.65^{*}$ & $18.49^{* * *}$ \\
\hline & 60 & 4.63 & 1.25 & 2.37 & 32.0 \\
\hline Mean & & 4.9 & 1.4 & 2.4 & 25 \\
\hline Control & & 3.96 & 1.01 & 2.04 & 42.6 \\
\hline 'TifSport' & 31 & $17.75^{* *}$ & 2.0 & 10.5 & \\
\hline Mean (29 plants) & & 16.12 & 2.0 & 10.04 & \\
\hline Control & & 16.0 & 2.0 & 10.0 & \\
\hline
\end{tabular}

$\overline{*, * *, * * * *}$ Significantly different from the control at $P \leq 0.05,0.01$, or 0.001 , respectively. 
observed in 'TifEagle'. A single entry (\#31) was significantly different $(\alpha=0.05 ; \mathrm{p}=$ 0.002 ) for plant height, with a mean of 17.75 cm compared to the 'TifSport' control, which was $16 \mathrm{~cm}$. However, this difference may not have practical significance. After two years in the field, 'TifSport'-derived regenerated plants were identical in appearance to and able to withstand the management practices of control 'TifSport'. TifSport plots were destroyed after the second year to free up field space and were not available at the time of flow cytometry analysis.

Our results using 'TifEagle' nodes for culture are in agreement with Zhang et al (2002), confirming that this source tissue is a suitable explant source for induction of embryogenic tissue. 'TifSport' immature inflorescences were also suitable for embryogenic tissue production; however, the limited flowering cycle, difficulty in determining when a large portion of the grass would contain immature inflorescences, and their unpredictable response rate were all drawbacks to using this explant source. $\mathrm{Li}$ and $\mathrm{Qu}$ (2002) were able to induce embryogenic tissue from inflorescences identified by the emergence of the flag leaf from cultivars Tifgreen and Savannah. With 'TifSport', inflorescences cultured at this stage did not respond to the tissue culture condition tested. There appeared to be a strong genotype effect in favor of 'TifEagle' for the ability to produce embryogenic tissue from nodes with the media tested since 'TifSport' did not respond to node culture. 'TifSport' inflorescence-derived embryogenic tissue was not stable with multiple transfers to fresh induction medium in the dark. It tended to revert to friable nonembryogenic tissue or senesce. Repetitive somatic embryogenesis was found to be possible with 'TifEagle' callus by reducing 2,4-D $(3.39 \mu \mathrm{M})$, during multiple transfers in the dark (data not shown). Others ( $\mathrm{Li}$ and Qu, 2002; Ahn et al., 1987) reported repetitive somatic embryogenesis and the ability to maintain embryogenic callus for long periods. With both genotypes, on rare occasions $(<10)$, albino plants were regenerated from embryogenic tissue. Genotype and culture conditions are likely factors in determining the frequency of albino plants and somaclonal variation present. $\mathrm{Li}$ and Qu (2002) and Chaudhury and Qu (2000) observed no albinos when plants were regenerated from tetraploid ('Savannah') and triploid ('Tifgreen') bermudagrass. Artunduaga et al. (1988) regenerated up to $90 \%$ albino plants using bermudagrass accession 10978b. Ahn et al. (1987) did not observe any variation in plants regenerated from 'Tifton 44', '74 X 126', and 'Tifway'. Genotype probably played a large role in the somaclonal variation observed with 'TifEagle' because Zhang et al. (2002) also observed somaclonal variation using the same genotype and explant, but different culture conditions. Since all the 'TifEagle'derived regenerated plants originated from a single piece of embryogenic tissue from a single node, the increase in ploidy probably occurred during the in vitro culture phase and was not already present in the explant. 'TifEagle'-derived plants are currently in a small-scale field test to determine if any merit further large-scale evaluation.

\section{Literature Cited}

Ahloowalia, B.S. 1975. Regeneration of ryegrass plants in tissue culture. Crop Sci. 15:449-452.

Ahloowalia, B.S. 1983. Spectrum of variation in somaclones of triploid rygrass. Crop Sci. 23:1141-1147

Ahn, B.J., F.H. Huang, and J.W. King. 1985. Plant regeneration through somatic embryogenesis in common bermudagrass tissue culture. Crop Sci. 25:1107-1109.

Ahn, B.J., F.H. Huang, and J.W. King. 1987. Regeneration of bermudagrass cultivars and evidence of somatic embryogenesis. Crop Sci. 27:594-597.

Artunduaga, I.R., C.M. Taliaferro, and B.L. Johnson. 1988. Effects of auxin concentration on induction and growth of embryogenic callus from young inflorescence explants of Old World bluestem (Bothriochloa spp.) and bermuda (Cynodon spp.) grasses. Plant Cell Tiss. Organ Cult. 12:13-19.

Artunduaga, I.R., C.M. Taliaferro, and B.L. Johnson.
1989. Induction and growth of callus from immature inflorescences of 'Zebra' bermudagrass as affected by casein hydrolysate and 2,4-D concentrations. In Vitro Cell. Dev. Biol.-Plant 25:753-756.

Chaudhury, A. and R. Qu. 2000. Somatic embryogenesis and plant regeneration of turf-type bermudagrass: Effects of 6-benzyladenine in callus induction medium. Plant Cell Tiss. Organ Cult. 60:113-120.

Choi, H.W., P.G. Lemaux, and M.J. Cho. 2000. Increased chromosomal variation in transgenic versus nontransgenic barley (Hordeum vulgare L.) plants. Crop Sci. 40:524-533.

Croughan, S.S., M. Quisenberry, M. Eichhorn, P. Coyler, and P. Brown. 1994. Registration of Brazos-R3 bermudagrass germplasm. Crop Sci. 34:542.

Goldman, J.J., W.W. Hanna, G.H. Fleming, and P. Ozias-Akins. 2003. Ploidy variation among herbicide-resistant bermudagrass plants of cv. TifEagle transformed with the bar gene. Plant Cell Rpt. DOI 10.1007/s00299-003-0736-0.

Hanna, W.W., R.N. Carrow, and A.J. Powell. 1997. Tift 94 turf bermudagrass. Crop Sci. 37:1012.

Hanna, W.W. and J.E. Elsner. 1999. TifEagle bermudagrass. Crop Sci. 39:1258

Li, L. and R. Qu. 2002. In vitro somatic embryogenesis in turf-type bermudagrass: Roles of abscisic acid and gibberellic acid, and occurrence of secondary somatic embryogenesis. Plant Breeding 121:155-158.

Murashige, T. and F. Skoog. 1962. A revised medium for rapid growth and bioassays with tobacco tissue cultures. Physiol. Plant. 15:473-497.

SAS Institute. 1999. The SAS system for Windows. Release 8.0. SAS Inst., Cary, N.C.

Taylor, M.G. and I.K. Vasil. 1996. Quantitative analysis of ultrastructural changes during zygotic and somatic embryogenesis in pearl millet (Pennisetum glaucum [L.] R. Br.). Sexual Plant Reprod. 9:286-298.

Zhang G.Y., S. Lu, T.A. Chen, C.R. Funk, and W. Meyer. 2002. Application of somaclonal variation in triploid bermudagrass breeding. In: Annual Meeting Abstracts 2002. Amer. Soc. Agron., Madison, Wis.

Zhang G.Y., S. Lu, T.A. Chen, C.R. Funk, and W. Meyer. 2003. Transformation of triploid bermudagrass (Cynodon dactylon $\mathrm{x}$ C. transvaalensis cv. TifEagle) by means of biolistic bombardment. Plant Cell Rpt. 21:860-864. 